\title{
Open questions on the mechanisms of neuromodulation with applied and endogenous electric fields
}

\author{
Shennan A. Weiss ${ }^{1 *}$ and Marom Bikson ${ }^{2}$ \\ ${ }^{1}$ Neurology, Columbia University, New York, NY, USA \\ ${ }^{2}$ Biomedical Engineering, The City College of New York of CUNY, New York, NY, USA \\ *Correspondence: saw2164@columbia.edu
}

Edited and reviewed by:

Hauke R. Heekeren, Freie Universität Berlin, Germany

Keywords: ephaptic, transcranial direct current stimulation (tDCS), transcranial magnetic stimulation, brain oscillation, stimulation, systems neuroscience

\section{INTRODUCTION}

Despite a long-standing recognition that bioelectric phenomena underpin brain function, fundamental questions remain about how extracellular current flow may influence neural activity and computation. The source of extracellular current flow may be exogenous, electrical exposure or stimulation, or the source may be endogenous, for currents produced by the brain itself. The former has recently gained increased urgency with the evolution of transcranial electrical therapy for a broad range of neurological and psychiatric disorders. The latter remains one of the longest standing open questions in neuroscience-is the electrical current flow that is a ubiquitous aspect of brain function (manifest for example in oscillations, EEG) an epiphenomenon or a key functional signal in the brain.

Field effects that are produced by transmembrane currents are called ephaptic. An ephapse "Gr: touching across" was originally coined to describe how two axons placed close together in mineral oil, which has a higher resistance than saline, transmit an action potential at what can be considered an artificial synapse (Katz and Schmitt, 1940; Arvanitaki, 1942). This finding led Sir John Eccles to propose the Golgi cell theory of inhibition in which he speculated that ephapses could mediate inhibitory neurotransmission (Brooks and Eccles, 1947). Eccles corrected this theory and was awarded a Nobel Prize for his subsequent work demonstrating that inhibitory neurotransmission is mediated by chemical synapses. However, in accord with Eccles original theory, ephaptic transmission has been found to mediate inhibitory neurotransmission at the Mauthner cell axon hillock (Weiss et al., 2008), and the Pinceau of the cerebellar Purkinje cell (Korn and Axelrad, 1980; Blot and Barbour, 2014). Research during the twenty-first century has demonstrated that field effects in the mammalian brain may be much more ubiquitous. Field effects generated by endogenous activity may influence network oscillations and computation throughout the cerebral cortex (Radman et al., 2007). Both physiologic (e.g., oscillations; Parra and Bikson, 2004) and pathologic (e.g., epilepsy; Haas and Jefferys, 1984) activity may be influenced by field effects. Because field effects are both generated by coherent population activity and influence networks in a coherent fashion, they may influence brain function as no neurotransmitter can.

Furthermore, weak direct and alternating current stimulation of the human cerebral cortex at low-intensity strengths have been found to influence network dynamics and behavior.
The exploration of transcranial Direct Current Stimulation (tDCS) and transcranial Alternative Current Stimulation (tACS) over the past decade for both treatment and to enhance cognitive performance and learning in healthy individuals, has galvanized questions about how the brain responds to low-intensity stimulation. Indeed, the intensity of electric generated in these modalities can approximate the intensity of electricity generated by the bran itself (Datta et al., 2009).

Thus the science of field-effects and low-intensity electrotherapy overlap. The articles included in this e-book highlight some of the latest developments in understanding both endogenous field effects in the central nervous system, as well as the mechanisms and clinical applications of transcranial stimulation of the cortex. We hope that these articles are helpful for students, researchers, and clinicians who hope to better understand and utilize this often overlooked form of neurotransmission.

\section{ACKNOWLEDGMENTS}

Dr. Weiss would like to acknowledge Dr. Donald Faber and Dr. Henri Korn.

\section{REFERENCES}

Arvanitaki, A. (1942). Effects evoked in an axon by the activity of a contiguous one. J. Neurophysiol. 5, 89-108.

Blot, A., and Barbour, B. (2014). Ultra-rapid axon-axon ephaptic inhibition of cerebellar Purkinje cells by the pinceau. Nat. Neurosci. 17, 289-295. doi: 10.1038/nn.3624

Brooks, C. M., and Eccles, J. C. (1947). Electrical hypothesis of central inhibition. Nature 159, 760-764. doi: 10.1038/159760a0

Datta, A., Bansal, V., Diaz, J., Patel, J., Reato, D., and Bikson, M. (2009). Gyri-precise head model of transcranial direct current stimulation: improved spatial focality using a ring electrode versus conventional rectangular pad. Brain Stimul. 2, 201 7, 207.e1. doi: 10.1016/j.brs.2009.03.005

Haas, H. L., and Jefferys, J. G. R. (1984). Low-Calcium field burst discharges of CA1 pyramidal neurons in rat hippocampal slices. J. Physiol. 354, 185-201.

Katz, B., and Schmitt, O. H. (1940). Electric interaction between two adjacent nerve fibres. J. Physiol. 97, 471-488.

Korn, H., and Axelrad, H. (1980). Electrical inhibition of Purkinje cells in the cerebellum of the rat. Proc. Natl. Acad. Sci. U.S.A. 77, 6244-6247. doi: 10.1073/pnas.77.10.6244

Parra, L. C., and Bikson, M. (2004). "Model of effect of extracellular fields on spike time coherence," in IEEE Engineering in Medicine and Biology Conference (New York, NY).

Radman, T., Su, Y., An, J. H., Parra, L. C., and Bikson, M. (2007). Spike timing amplifies the effect of electric fields on neurons: implications for endogenous field effects. J. Neurosci. 27, 3030-3036. doi: 10.1523/JNEUROSCI.009507.2007 
Weiss, S. A., Preuss, T., and Faber, D. S. (2008). A role of electrical inhibition in sensorimotor integration. Proc. Natl. Acad. Sci. U.S.A. 105, 18047-18052. doi: 10.1073/pnas.0806145105

Conflict of Interest Statement: The authors declare that the research was conducted in the absence of any commercial or financial relationships that could be construed as a potential conflict of interest.

Received: 23 December 2013; accepted: 31 March 2014; published online: 17 April 2014.
Citation: Weiss SA and Bikson M (2014) Open questions on the mechanisms of neuromodulation with applied and endogenous electric fields. Front. Hum. Neurosci. 8:227. doi: 10.3389/fnhum.2014.00227

This article was submitted to the journal Frontiers in Human Neuroscience.

Copyright (c) 2014 Weiss and Bikson. This is an open-access article distributed under the terms of the Creative Commons Attribution License (CC BY). The use, distribution or reproduction in other forums is permitted, provided the original author(s) or licensor are credited and that the original publication in this journal is cited, in accordance with accepted academic practice. No use, distribution or reproduction is permitted which does not comply with these terms. 